\title{
AVALIAÇÃO DAS MANIFESTAÇÕES PATOLÓGICAS EM REVESTIMENTOS ENCONTRADAS NO BLOCO "A” DA ESCOLA POLITÉCNICA DE PERNAMBUCO
}

\author{
VIANA, CLAUDIA CAVALCANTI LOPES \\ Bacharel em arquitetura e urbanismo \\ Universidade Federal de Pernambuco \\ Pernambuco; Brasil \\ clauviana@hotmail.com
}

\author{
SILVA, MARIA ANGÉLICA VEIGA DA \\ Bacharel em engenharia civil \\ Univerdidade de Pernambuco \\ Pernambuco; Brasil \\ angelica_veiga@hotmail.com
}

\author{
PÓVOAS, YÊDA VIEIRA \\ Professora Doutora \\ Universidade de Pernambuco \\ Pernambuco; Brasil \\ yeda.povoas@gmail.com
}

\author{
LORDSLEEM, ALBERTO CASADO JR \\ Professor Doutor \\ Universidade de Pernambuco \\ Pernambuco; Brasil \\ acasado@poli.br
}

\section{RESUMO}

A Escola Politécnica de Pernambuco faz parte da história do Estado, e o Bloco A é a representação física do passar do tempo e da importância dessa instituição. O presente estudo apresenta um levantamento das manifestações de revestimentos do edifício. Para o desenvolvimento da pesquisa foi realizada uma vistoria no local para levantamento das áreas afetadas da edificação através da identificação em croqui e de registros fotográficos, realizados inclusive com uso de drone. A partir das análises foi possível verificar que as manifestações patológicas de revestimento mais recorrentes tanto na área externa quanto na área interna foram os descolamentos que representaram $34 \%$ do total de patologias encontradas. Os resultados mostraram que essa manifestação ocorreu pela ausência de manutenção preventiva, com isso é necessário além da correção das manifestações patológicas encontradas a criação de um programa de manutenção para as áreas de revestimento do edifício.

Palavras-chaves: Manifestações patológicas, revestimentos, manutenção preventiva.

\begin{abstract}
The Pernambuco Polytechnic School is part of the history of the state, and Block A is the physical representation of the passage of time and the importance of this institution. This study presents a survey of the building coatings manifestations. For the development of the research a survey was carried out on the site to survey the affected areas of the building through the identification in sketch and photographic records, including the use of drone. From the analysis it was possible to verify that the most recurrent pathological manifestations of coating in both the external and internal areas were the detachments that represented $34 \%$ of the total pathologies found. The results showed that this manifestation occurred due to the absence of preventive maintenance, so it is necessary, besides the correction of the pathological manifestations found, the creation of a maintenance program for the cladding areas of the building.
\end{abstract}

Keywords: Pathological manifestations, coatings, preventive maintenance. 


\section{INTRODUÇÃO}

A Escola Politécnica de Pernambuco foi criada em 06 de março de 1912, com a publicação, no Diário Ofícial, do seu primeiro estatuto. Em janeiro de 1952 ela se agregou à Universidade Católica de Pernambuco - UNICAP, criando aquela que seria a terceira Universidade do Estado. Em 1966 a POLI se incorporou à Fundação de Ensino Superior de Pernambuco - FESP, e a partir desta data, participou da luta pela criação da quarta universidade do estado, a Universidade de Pernambuco - UPE, o que ocorreu em 1990, com o seu reconhecimento pelo MEC. (FILHO, Armando, 1981).

O Bloco A da Escola Politécnica de Pernambuco é o edifício que sempre acolheu a história da Universidade, e demonstra em sua arquitetura não só a memória acadêmica, mas também a ação do tempo em uma construção antiga e todas as cosequências que ele pode trazer a uma estrutura física, em forma de manifestações patológicas.

As manifestações patológicas ocorrem quando uma edificação apresenta algum problema em sua integridade, comprometendo o desempenho do edifício ou de uma de suas partes por meio de sinais externos, sintomas, indicando que algo não está correto. Surge então a necessidade de estudar estes sinais com o objetivo de diagnosticar a manifestação ou problema patológico. Para se efetuar um diagnóstico correto faz-se necessário realizar, inicialmente, uma inspeção visual e uma coleta de dados, identificando todos os sintomas observados (TUTIKIAN e PACHECO, 2013).

De acordo com Azevedo (2011, apud MONTEIRO, 2017), pode-se afirmar que as manifestações patológicas têm suas origens motivadas por falhas ocasionadas durante uma ou mais fases dos processos que permeiam a construção civil, sejam provenientes da fase de projeto, execução ou utilização da construção.

Geralmente, quando desenvolvidas, essas patologias são facilmente percebidas nos revestimentos. Ao contrário do que parece, a função do revestimento é proteger as partes principais (estruturas e alvenarias) da edificação, normalmente cobrindo-as, em camadas sobrepostas, com os mais diversos tipos de materiais apropriados, de modo a evitar que estas partes, ou seus componentes, sejam afetados pelos fatores externos e internos, aumentando a vida útil da edificação.

As manifestações patológicas em revestimentos mais recorrentes foram:

Fissuras: fraturas ou descontinuidades nos materiais ocasionadas quando as tensões provenientes das variações dimensionais ultrapassam a capacidade de resistência do material solicitado. (GASPAR et al, 2006 apud ASSUNÇÃO, 2019)

Thomas (1989), apud Rocha e Monteiro (2017) alerta para três aspectos relevantes que necessitam ser considerados mediante a fissuração dos edifícios: (i) o comprometimento do desempenho da obra em serviço (estanqueidade à água, durabilidade, desempenho térmico, etc.), (ii) o constrangimento psicológico que a fissuração do edifício exerce sobre seus usuários e (iii) o aviso de um eventual estado de perigo.

As fissuras podem ser classificadas, de acordo com a NBR 13749 (ABNT, 2013), quanto à forma em geométricas ou mapeadas, e quanto à atividade em ativas ou passivas.

As fissuras geométricas podem ter origem a partir de algum dano ocorrido na alvenaria ou também das juntas de assentamento das mesmas. As fissuras mapeadas podem ser originárias da retração das argamassas, por excesso de finos no traço, secagem rápida ou por excesso de desempenamento (SAHADE, 2005).

As fissuras ativas são assim denominadas por apresentarem variações sensíveis e intermitentes de abertura e fechamento e as fissuras passivas não apresentam variações sensíveis ao longo do tempo, podem ser consideradas estabilizadas. (SAHADE, 2005).

Descolamentos: segundo Silva (2014), descolamentos em superfícies revestidas com placas cerâmicas são caracterizados pela perda de aderência das placas cerâmicas do substrato, ou da argamassa colante, quando as tensões surgidas no revestimento ultrapassam a capacidade de aderência das ligações entre a placa cerâmica e argamassa colante e/ou emboço. O descolamento em revestimento argamassado caracteriza-se pela queda do revestimento causada pela falta de aderência deste com base de aplicação, geralmente em função das características da superfície, do tipo de argamassa empregada, do processo de execução e das condições climáticas. 
Desagregação: é definida pela perda de coesão dos elementos da argamassa. Ocorre através do desprendimento do material que se esfarela em forma de pó ou grânulos. Está diretamente relacionado à pequena resistência mecânica do reboco.

Eflorescência ou criptoflorescência: a eflorecência ocorre quando depósitos salinos se formam na superfície, resultantes da migração e posterior evaporação de soluções aquosas salinizadas, deixando estas formações na superfície dos materiais (LANNES, 2011). Na criptoflorecência a cristalização dos sais solúveis exercem pressões em interfaces e no interior dos materiais que constituem o revestimento, causando a desagregação de toda a massa, com perdas de resistência notáveis. (ROCHA e MONTEIRO 2017). Na maior parte dos casos as eflorescências não causam problemas maiores que o mau aspecto resultante, porém, na criptoflorecência o sal formado pode levar a lesões tais como o descolamento dos revestimentos ou pinturas, a desagregação das paredes e até a queda de elementos construtivos.

Umidade: a presença de umidade nas edificações institui-se como uma das principais causas de degradação. Os materiais utilizados nos sistemas de fachada devem ser estanques à água e, simultaneamente permitir as trocas de vapor de forma que a umidade dos materiais não permaneça aprisionada (ZANONI, 2015).

De acordo com Nappi (2002) apud Giordani (2016) a umidade pode ser classificada em cinco tipos, a partir da sua origem: umidade da obra, proveniente do processo de construção; umidade ascendente, originada da absorção da água proveniente do solo, que migra para as construções por capilaridade; umidade de infiltração, proveniente da água de chuva; umidade de condensação, quando o vapor de água do ambiente condensa ao entrar em contato com uma superfície de temperatura inferior; E umidade acidental, originada de vazamentos ou rompimento de instalações hidráulicas ou outros dispositivos da edificação.

Microrganismos: de acordo com Moresco et al. (2015), a biodeterioração pode ser conceituada como qualquer alteração que não favoreça as superfícies, causadas por organismos que as usam como ambiente de desenvolvimento. A atividade vital dos organismos ocorre em áreas onde existe a presença de umidade e corroboram com a deterioração da superficie. O material constituinte da formulação das tintas, algumas vezes, fornece os nutrientes para microrganismos. Como as fachadas são submetidas diretamente a fatores naturais, essa ação é comum nas superfícies das edificações que possibilitam um ambiente ideal para agentes microbiológicos que conseguem sobreviver por longos períodos em diversas condições.

Vegetação Parasita: de acordo com Flores-Colen (2005), apud Assunção (2019) as manchas de vegetação parasitária são ocasionadas pela presença de microrganismos biológicos como algas, líquens e musgos.

Os processos biológicos podem resultar do ataque químico de ácidos (produção de anidrido carbônico) gerados pelo crescimento de raízes de plantas ou de algas que se instalem em fissuras ou grandes poros, ou por ação de fungos, ou pela ação de sulfetos presentes nos esgotos (BRICK, MOREIRA e KRÜGER, 2013), causando a perda estética da fachada por escurecimento e a perda da integridade química dos materias que a compõe.

Sujidades: São a acumulação na superfície de material estranho de diversas naturezas (poeiras, fuligem e outras partículas poluentes), com espessura variável, pouco aderente e de fraca coesão, provenientes do próprio revestimento, do meio ambiente ou do suporte de aplicação (ASSUNÇÃO, 2019).

O objetivo deste trabalho é identificar as principais manifestações patológicas de revestimentos presentes no Bloco A, bem como identificar suas possíveis origens e causas, além de sugerir a metodologia mais indicada para a sua recuperação e a apresentação de um modelo de programa de manutenção preventiva. Também será apresentado um mapa de danos da edificação, assim como dados estatísticos sobre a frequência com que cada uma das manifestações patológicas de revestimento ocorre no Bloco A da POLI.

\section{METODOLOGIA}

A pesquisa foi conduzida em cinco etapas:

Etapa 01: Revisão literária relacionada ao tema;

Etapa 02: Elaboração de um croqui com a planta baixa e fachadas do Bloco A;

Etapa 03: Inspeção em campo com coleta de dados e levantamento fotográfico;

Etapa 04: Análise dos dados;

Etapa 05: Compilação dos resultados e relatório fotográfico. 
Inicialmente foi realizada uma revisão da literatura relacionada ao tema e elaborados os cróquis com as plantas baixas e de fachadas do Bloco A, apresentadas juntamente com uma legenda de cada uma das manifestações patológicas em revestimentos para que fossem facilmente identificadas. Estes cróquis foram utlilizados em campo para a inspeção visual e identificação das manifestações patológicas.

Para obtenção do levantamento fotográfico nas fachadas foi utilizado o Drone Phantom 4 Pro V2.0 que possui um sistema de transmissão OcuSync HD, que suporta comutação automática de banda de frequência dupla e se conecta ao DJI Goggles sem fio, além disso, seu sistema Flight Autonomy inclui sensores duplos de visão traseira e sistemas de sensor infravermelho para um total de 5 direções para de detecção de obstáculos e 4 direções de prevenção de obstáculos.

Normalmente esses equipamentos são projetados para tomar fotos de cima para baixo, fazendo levantamento de elementos no solo, porém para a atividade em questão, o ideal seria que as fotos fossem realizadas perpendicularmente à superfície da fachada. Como existiam obstáculos periféricos às fachadas, impedindo o Drone Phantom 4 Pro V2.0 de realizar a varredura total nas faces da edificação, o levantamento fotográfico foi complementado através de máquina fotográfica.

Após a análise dos dados obtidos foi confeccionado um mapa de danos para as áreas da fachada, além da locação em planta das manifestações patológicas em revestimentos identificadas internamente. A partir daí, cada uma destas manifestações foi apresentada individualmente, sendo elucidada sua provável origem e causa bem como uma recomendação de recuperação, além da proposição de um modelo de programa de manutenção preventiva para os elementos correlacionados com revestimentos. Também foi feita uma compilação dos quantitativos e das informações das patologias encontradas através do software Excel. Todas as informações obtidas foram resumidas em planilhas de onde foram elaborados gráficos que serão apresentados nos resultados.

\section{RESULTADOS}

O Bloco A é basicamente feito de estrutura de alvenaria resistente, com poucas peças em concreto armado, possuindo térreo e $1^{\circ}$ andar com área aproximada de $500,00 \mathrm{~m}^{2}$.

O Bloco A possui suas fachada guarnecidas por alpendres e portas pesadas de madeira. Seu revestimento é argamassado, com acabamento em pintura e alguns trechos da fachada frontal está azulejada em róseo. A sua coberta é formada por uma estrutura de madeira com telhas de fibrocimento. As fachadas do Bloco A podem ser verificadas nas figuras $01 \mathrm{a}, \mathrm{b}, \mathrm{c}$ e d.

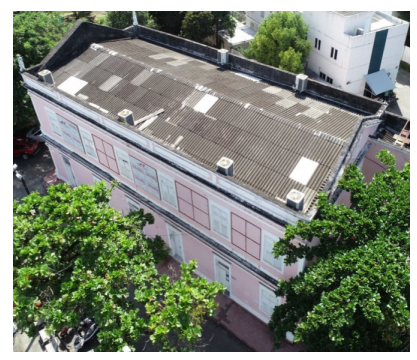

Figura 01 (a) - vista superior da fachada

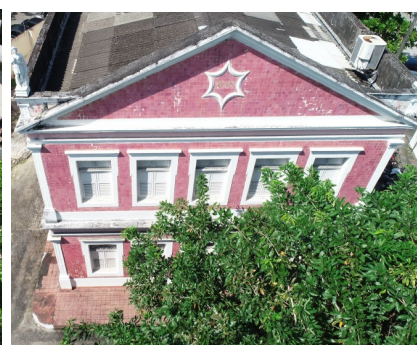

Figura 01 (b) - vista da fachada nordeste

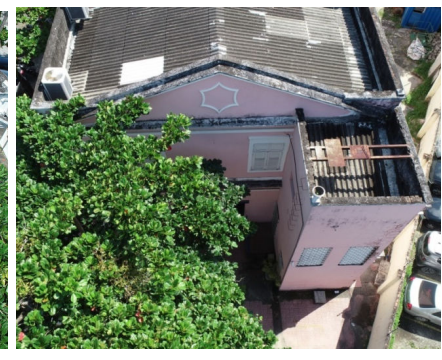

Figura 01 (c) vista da fachada sudoeste

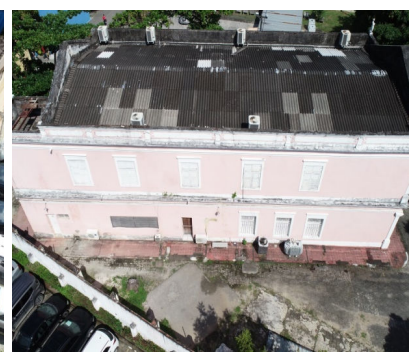

Figura 01 (d) vista da fachada sudeste

No andar térreo encontra-se o hall que dá acesso ao auditório, o laboratório de informática, a secretaria geral da pós graduação stricto sensu, uma sala de aula e o NAPSI (Núcelo de Apoio Psicopedagógico Inclusivo) que se subdivide através de divisórias de gesso em recepção, sala de reunião e sala de aula. No primeiro andar encontram se o hall, uma copa, o auditório, uma sala de apoio, o depósito e um banheiro.

O piso interno é formado por diversos materiais, dependendo da área da edificação, sendo eles: concreto regularizado, placas de concreto, paralelepípedos e revestimento cerâmico; As paredes internas em geral são em revestimento argamassado, mas também foram observados em alguns locais cerâmica e revestimento em gesso.

Foram encontradas diversas manifestações patológicas de revestimento, distribuídas nas áreas de fachada e internas. As Figuras 02 à 08 apresentam a localização destes danos no edifício, conforme descrito na legenda. 
FISSURA

DESTACAMENTO

DESAGREGAÇÃO

CRIPTOFLORESCÊNCIA

UMIDADE

MICROORGANISMOS/MOFO/BOLOR

VEGETAÇÃO PARASITA

SUJIDADES

Figura 02: Legenda

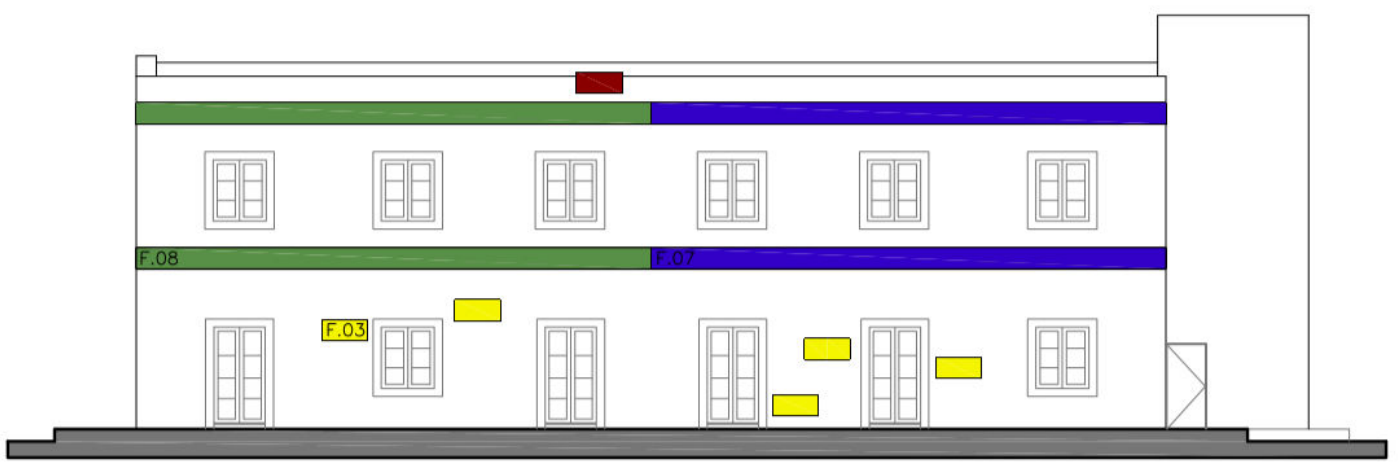

Figura 03: Fachada Noroeste

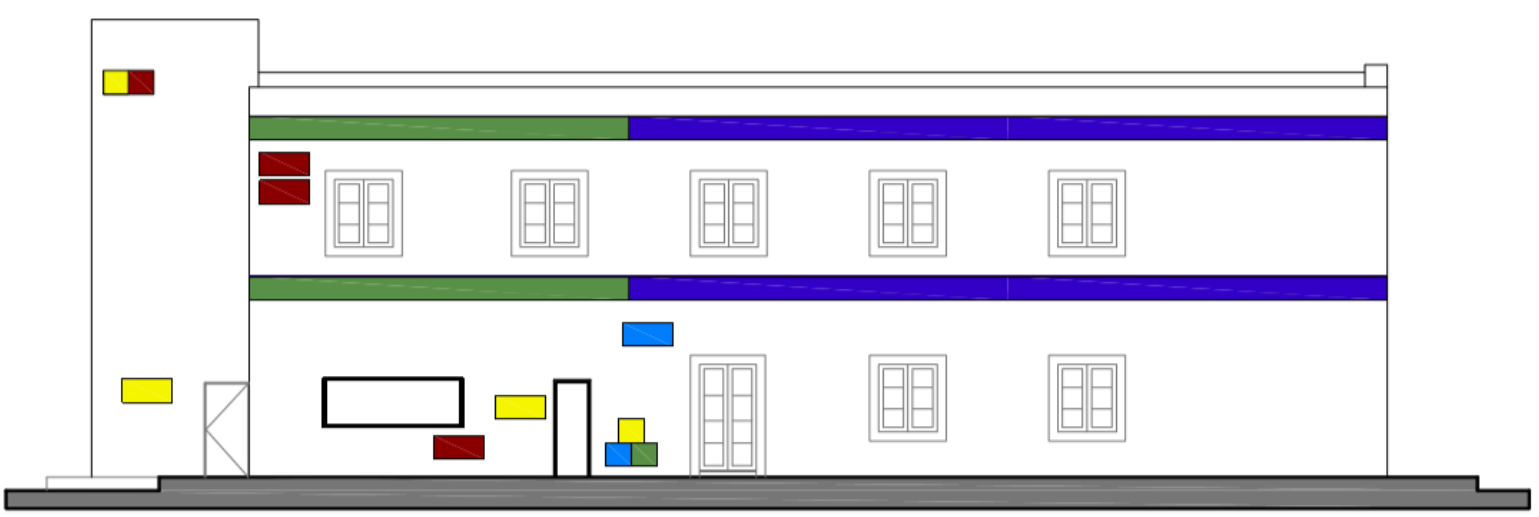

Figura 04: Fachada Sudeste

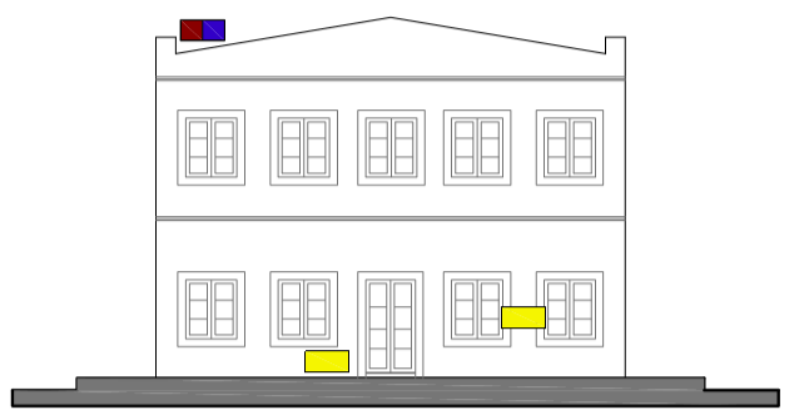

Figura 05: Fachada Nordeste

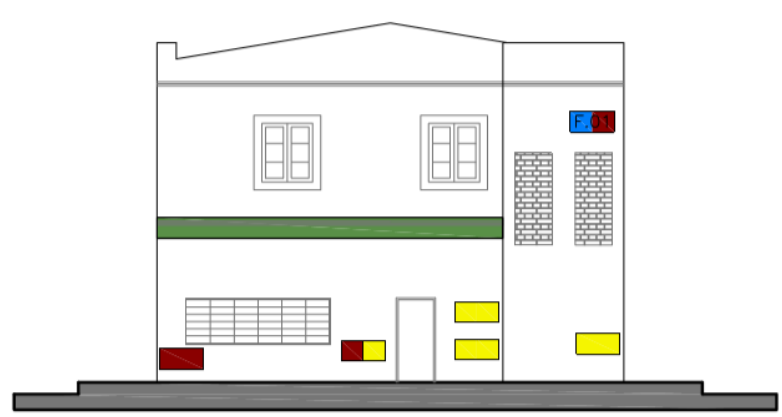

Figura 06: Fachada Sudoeste 


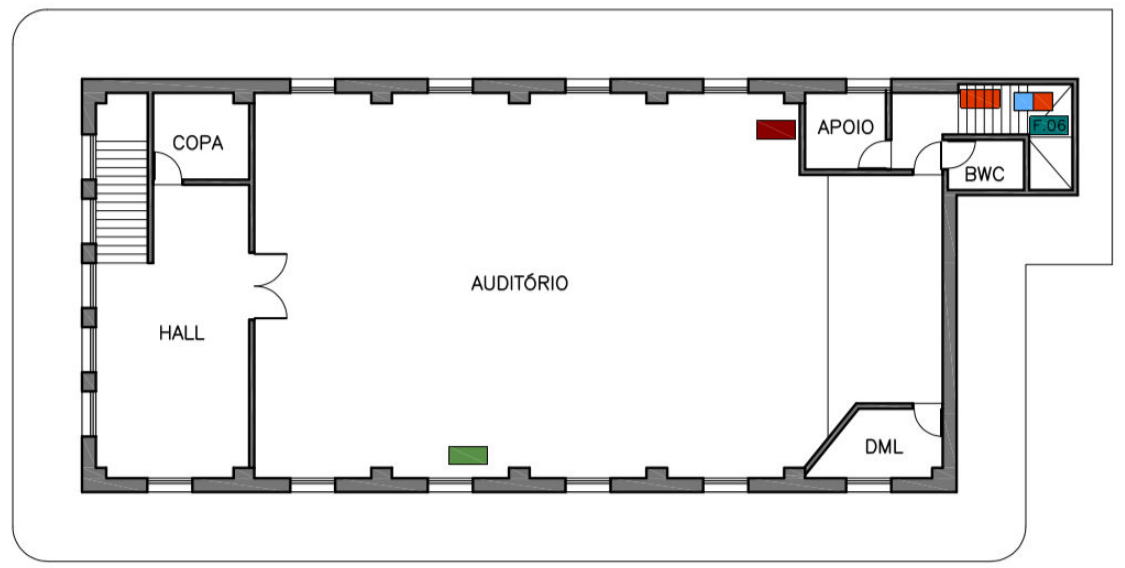

Figura 07: Planta baixa do pavimento térreo

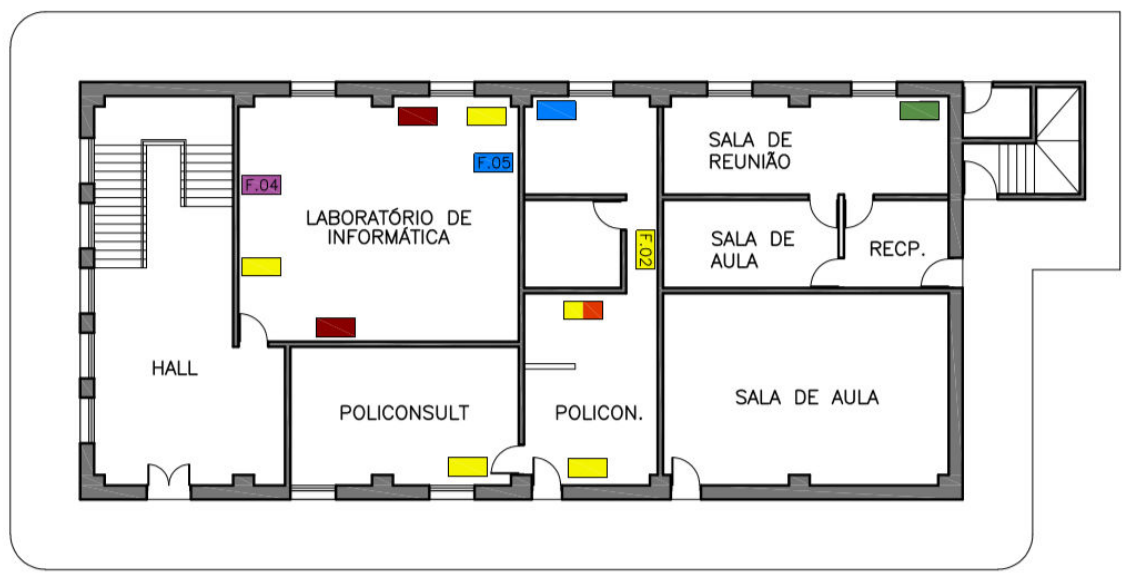

Figura 08: Planta baixa do $1^{\circ}$ pavimento

As Figuras 09 à 16 são apresentadas em conjunto com o tipo de dano, sua provável origem, provável causa e sugestão de recuperação. A sua localização aparece nas Figuras de Planta Baixa e Croqui.

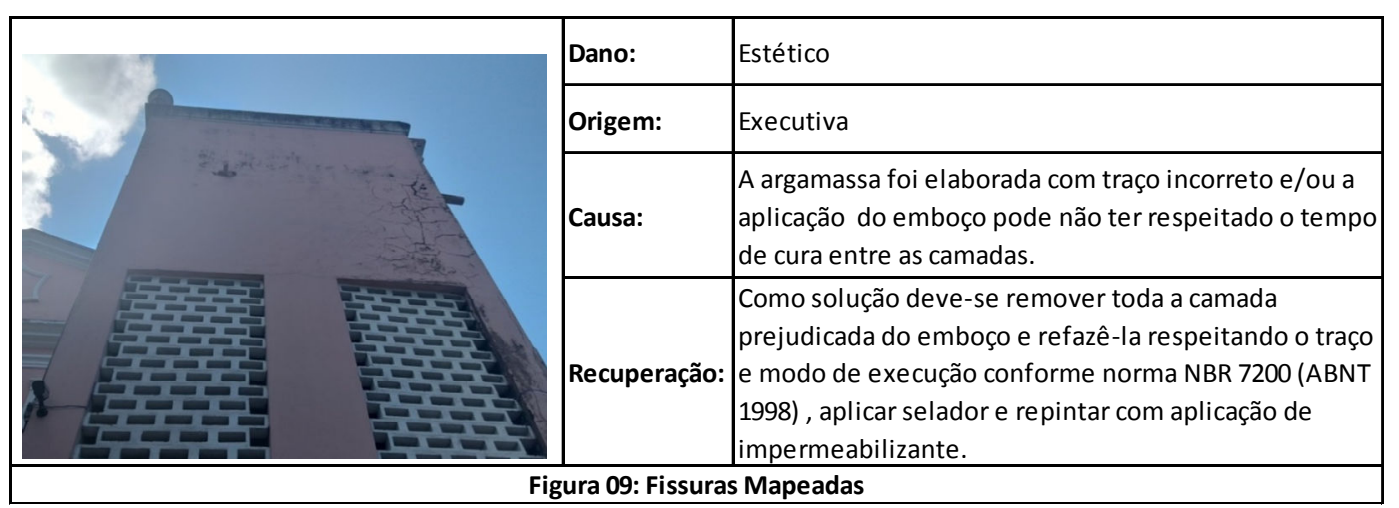




\section{СВРAT 2020

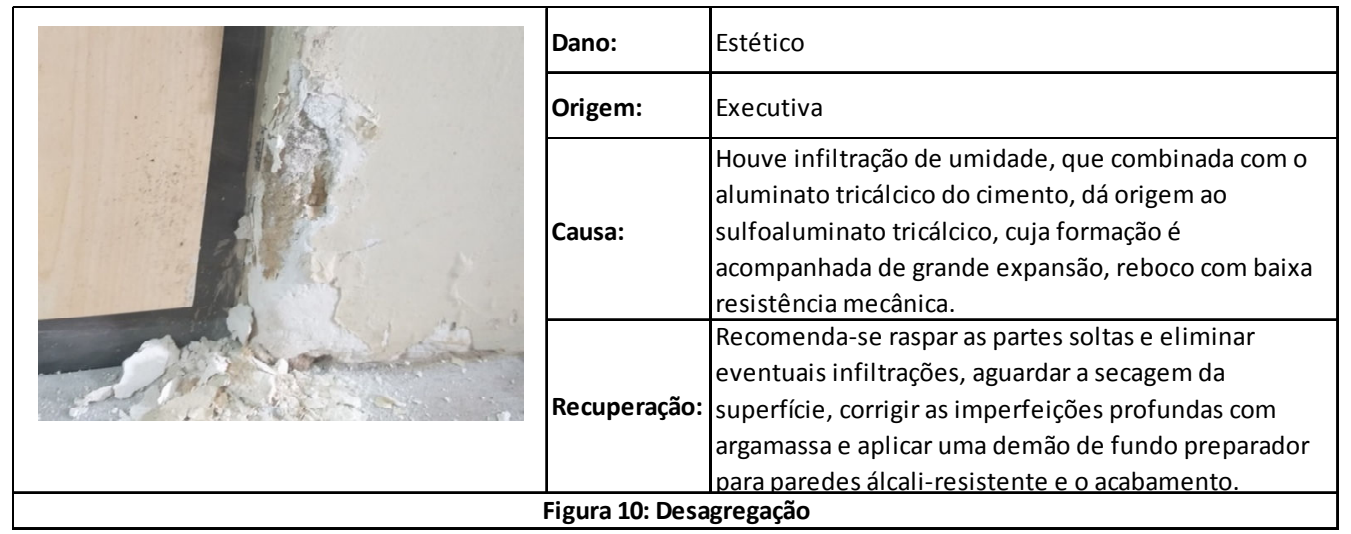

\begin{tabular}{|l|l|l|}
\hline & Dano: & Estético \\
\cline { 2 - 3 } & Origem: & Executiva \\
\cline { 2 - 4 } & Causa: & $\begin{array}{l}\text { Falta de aderência do revestimento à base, devido as } \\
\text { características da superfície, o tipo de argamassa } \\
\text { empregada, o processo de execução e as condições } \\
\text { climáticas. }\end{array}$ \\
\hline Recuperação: & $\begin{array}{l}\text { Recomenda-se raspar as partes soltas e realizar } \\
\text { procedimentos de preparo da base, como tratamentos } \\
\text { das superfícies de concreto e uso da camada de } \\
\text { preparação (chapisco). Além disso, é importante } \\
\text { garantir que não existe nenhum tipo de contaminação } \\
\text { na área a ser revestida. }\end{array}$ \\
\hline
\end{tabular}

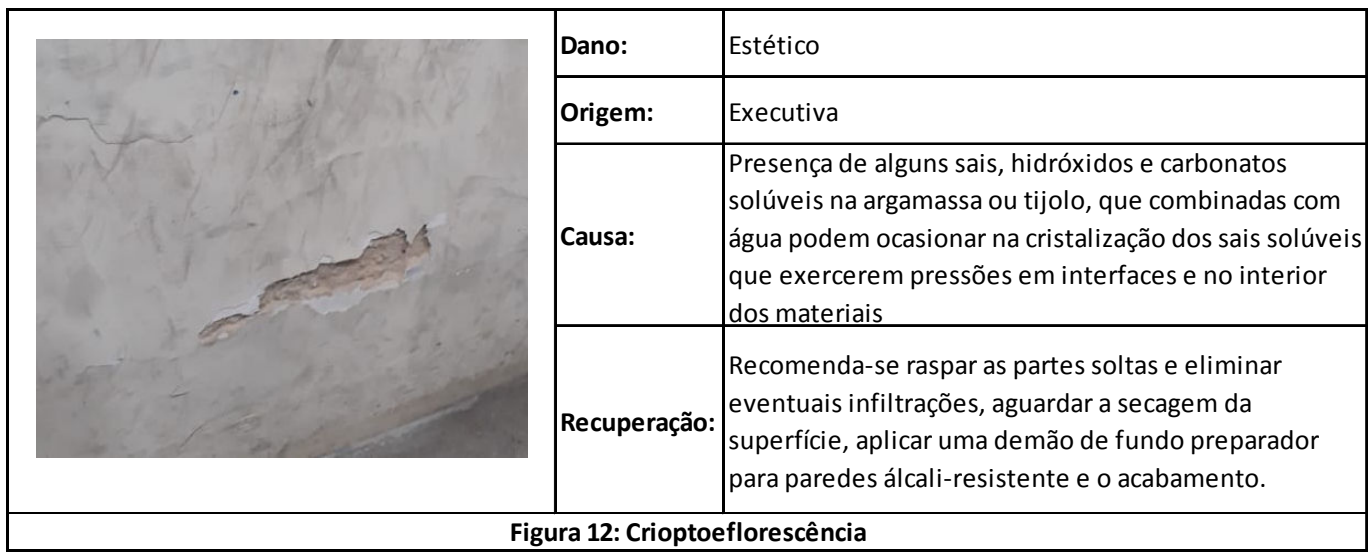

\begin{tabular}{|l|l|l|}
\hline \multirow{2}{*}{ Dano: } & Estético \\
\cline { 2 - 4 } & Origem: & Executiva \\
\cline { 2 - 4 } & Causa: & Fenômenos de higroscopicidade e/ou causas fortuitas. \\
\cline { 2 - 3 } & Recuperação: & $\begin{array}{l}\text { Recomenda-se eliminar eventuais infiltrações, } \\
\text { aguardar a secagem da superfície, aplicar uma demão } \\
\text { de fundo preparador para paredes álcali-resistente e o } \\
\text { acabamento. }\end{array}$ \\
\hline & Figura 13: Umidade \\
\hline
\end{tabular}




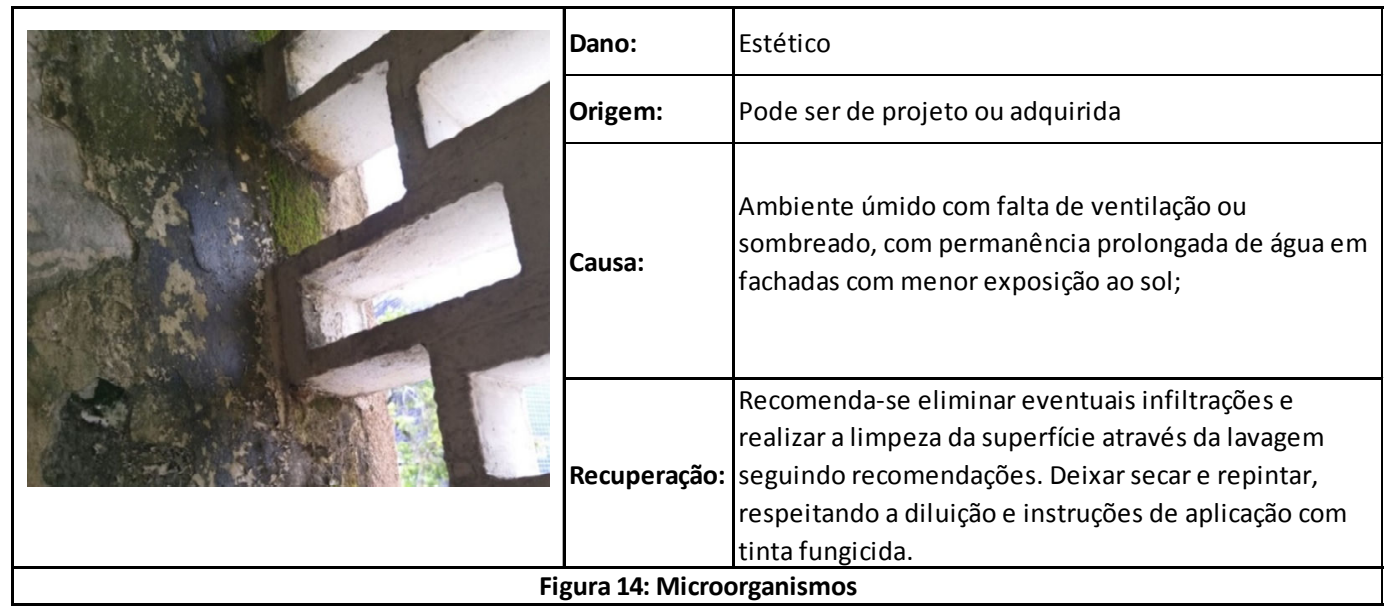

\begin{tabular}{|c|c|c|}
\hline & Dano: & Estético \\
\hline & Origem: & Adquirida \\
\hline$=$ & Causa: & $\begin{array}{l}\text { Presença de umidade, em conjugação com a radiação } \\
\text { solar que serve de fonte de energia, a vegetação se } \\
\text { desenvolve onde encontra um substrato adequado ao } \\
\text { seu crescimento }\end{array}$ \\
\hline & Recuperação: & $\begin{array}{l}\text { Recomenda-se eliminar eventuais infiltrações, } \\
\text { aguardar a secagem da superfície, aplicar uma demão } \\
\text { de fundo preparador para paredes álcali-resistente e o } \\
\text { acabamento. }\end{array}$ \\
\hline \multicolumn{3}{|c|}{ Figura 15: Vegetação Parasita } \\
\hline
\end{tabular}

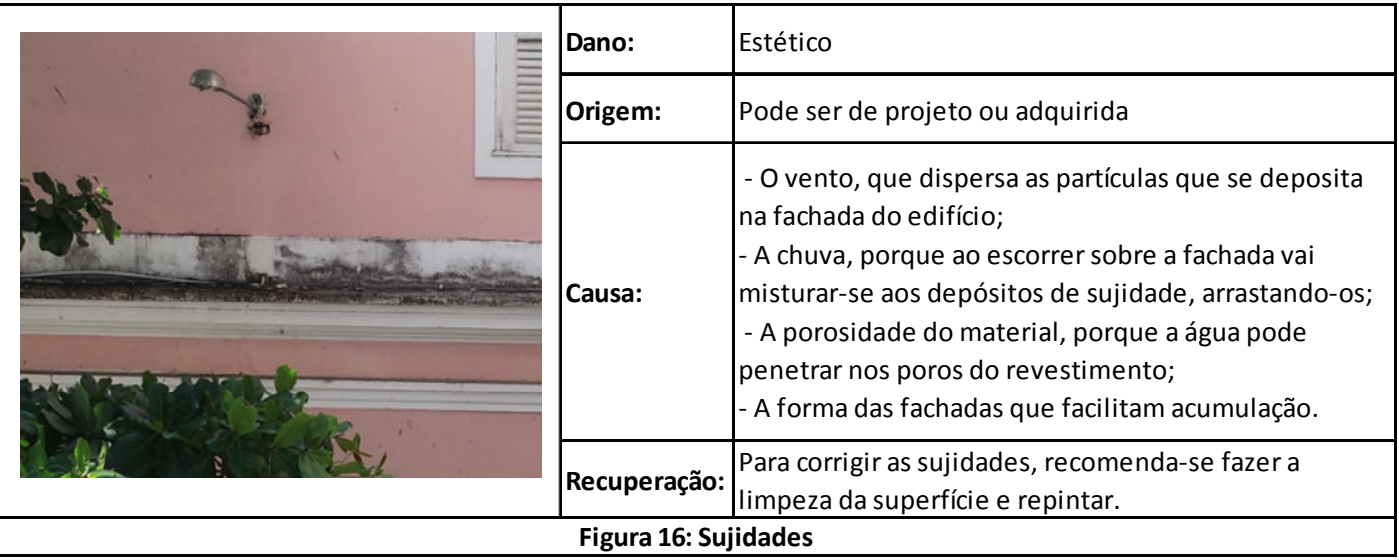

A partir dos dados levantados foi possível identificar que tanto nas áreas de fachada quanto nas internas a anomalia mais frequente foi o descolamento. As figuras 17, 18 e 19 apresentam os gráficos com a porcentagem específca de cada manifestação patológica segmentada por áreas, interna e de fachada. 


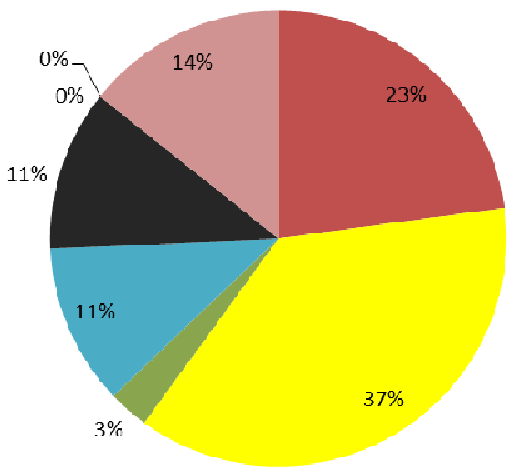

- rissura

Descolamento

ne Desagregação

- Sujidades

- IJmidade

Criptoflorescencia

Microrganismos

Vegelação Parasila

Figura 17: Percentual das manifestações patológicas na área das fachadas

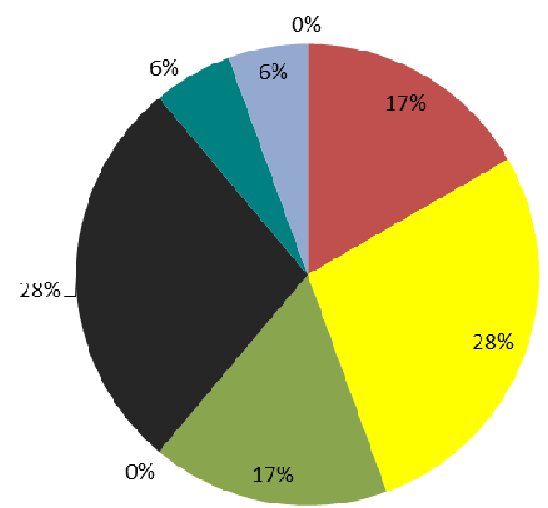

$$
\begin{aligned}
& \text { - Гissura } \\
& \text { Lescolamento } \\
& \text { - Desagregação } \\
& \text { - sujidades } \\
& \text { - Umidade } \\
& \text { - criptoflorescencia } \\
& \text { - Microrganismos } \\
& \text { - Vegetaçäo Parasita }
\end{aligned}
$$

Figura 18: Percentual das manifestações patológicas na área interna

As patologias de revestimentos mais representativas foram os descolamentos com $34 \%$, as fissuras, com $21 \%$ e a umidade com 17\% (Gráfico 03). Da quantidade total de manifestações patológicas encontradas, as que foram verificadas nas áreas das fachadas correspondem a $63,6 \%$ do quantitaivo geral de manifestações patológicas.

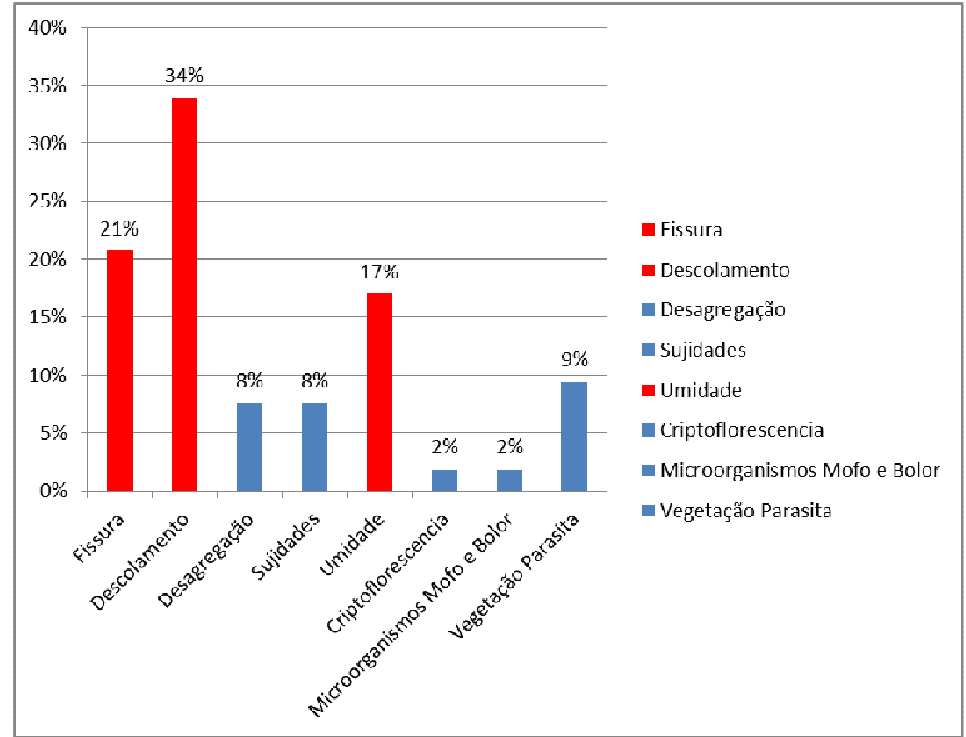

Figura 19: Percentual correspondente das manifestações patológicas identificadas 
Segundo a NBR 5674 (ABNT, 2012), a manutenção preventiva é caracterizada por serviços cuja realização seja programada com antecedencia, priorizando as solicitações dos usuários, estimativas de durabilidade esperada dos sistemas, elementos ou componentes das edificações em uso, gravidade e urgência, e relatórios de verificações periódicas sobre o seu estado de degradação.

Para que ela seja realizada é necessário que se crie um programa, que consiste na determinação das atividades essenciais de manutenção, sua periocidade, responsáveis pela execução, documentos de referência, referências normativas e recursos necessários, todos referidos individualmente aos sistemas, e quando são aplicáveis aos elementos, componentes e equipamentos. O programa de manutenção deve especificar se os serviços devem ser realizados por empresa capacitada, empresa especializada ou equipe de manutenção local.

A figura 20 representa um quadro esquemático que apresenta um modelo de programa de manutenção para os elementos correlacionados com revestimento, que pode ser empregado no estudo de caso.

Figura 20- Programa de manutenção preventiva para elementos correlacionados com revestmentos

\begin{tabular}{|c|c|c|c|c|}
\hline Periodicidade & Sistema & Elemento/Componente & Atividade & Responsável \\
\hline A cada mês & $\begin{array}{l}\text { Revestimentos de } \\
\text { Paredes e pisos }\end{array}$ & $\begin{array}{c}\text { Pedras naturais } \\
\text { (mármore, granito e } \\
\text { outros) }\end{array}$ & $\begin{array}{l}\text { Verificar e se necessário, encerar as peças } \\
\text { polidas }\end{array}$ & Equipe de manutenção local \\
\hline A cada mês & $\begin{array}{l}\text { Sistemas } \\
\text { hidrossanitários }\end{array}$ & Calhas e canaletas & $\begin{array}{l}\text { Limpar o sistema das água pluviais e ajustar a } \\
\text { periocidade em função da sazonalidade, } \\
\text { especialmente em época de chuvas intensas }\end{array}$ & Equipe de manutenção local \\
\hline A cada ano & \multicolumn{2}{|c|}{ Rejuntamentos e vedações } & $\begin{array}{l}\text { Verificar sua integridade e recosntituir os } \\
\text { rejuntamentos internos e externos dos pisos, } \\
\text { parede, peitoris, soleiras, ralos, peças } \\
\text { sanitárias, bordas de banhiras, chamines, } \\
\text { grelhas de ventilação e outros elementos }\end{array}$ & $\begin{array}{c}\text { Equipe de manutenção local / } \\
\text { Empresa capacitada }\end{array}$ \\
\hline A cada ano & Impermeabilização & $\begin{array}{c}\text { Reservatórios, } \\
\text { coberturas, jardins } \\
\text { suspensos }\end{array}$ & $\begin{array}{c}\text { Verificar sua integridade e recosntituir a } \\
\text { proteção mecânica, sinais de infiltração ou } \\
\text { falhas da impermeabilização exposta }\end{array}$ & Equipe de manutenção local \\
\hline \multirow[b]{2}{*}{ A cada ano } & \multirow{2}{*}{$\begin{array}{l}\text { Revestimentos de } \\
\text { paredes e pisos }\end{array}$} & $\begin{array}{l}\text { Paredes externas/ } \\
\text { fachadas e muros }\end{array}$ & $\begin{array}{l}\text { Verificar sua integridade e recosntituir onde } \\
\text { necessário }\end{array}$ & $\begin{array}{c}\text { Equipe de manutenção local / } \\
\text { Empresa capacitada }\end{array}$ \\
\hline & & \begin{tabular}{|c|}
$\begin{array}{c}\text { Piso acabado, } \\
\text { revestimento de paredes } \\
\text { e tetos }\end{array}$ \\
\end{tabular} & $\begin{array}{l}\text { Verificar sua integridade e recosntituir onde } \\
\text { necessário }\end{array}$ & $\begin{array}{c}\text { Equipe de manutenção local / } \\
\text { Empresa capacitada }\end{array}$ \\
\hline $\begin{array}{l}\text { A cada três } \\
\text { anos }\end{array}$ & \multicolumn{2}{|r|}{ Fachada } & $\begin{array}{l}\text { Efetuar lavagem, verificar os elementos e, se } \\
\text { necessário, solicitar inspeção. Atender às } \\
\text { prescrições do relatório ou laudo de inspeção }\end{array}$ & $\begin{array}{l}\text { Equipe de manutenção local / } \\
\text { Empresa capacitada / Empresa } \\
\text { especializada }\end{array}$ \\
\hline
\end{tabular}

Fonte: NBR 5674 (ABNT 2012) adaptado pelas AUTORAS

\section{CONSIDERAÇÕES FINAIS}

Tendo em vista a importância histórica e acadêmica da POLI, principalmente para a Engenharia Civil no Estado de Pernambuco, este trabalho abordou a ocorrência de manifestações patológicas nos de fachadas e internos do Bloco A da Escola Politécnica de Pernambuco.

As vistorias realizadas mostraram que as fachadas apresentaram uma maior quantidade de anomalias identificadas, 0 que era esperado visto que as variáveis ambientais específicas do meio externo é mais agressivo.

As manifestaçôes patológicas de maior recorrência no edifício foram os descolamentos, as fissuras e a umidade, que no quantitativo total dos danos identificados, correspondem respectivamente a $34 \%, 21 \%$ e $17 \%$. Tanto nas fachadas quanto nas áreas internas, a anomalia de maior representatividade foi o descolamento com $37 \%$ e $28 \%$, respectivamente.

A identificação e correção das possíveis falhas, além de contribuir para aumentar a vida útil dos revestimentos, certamente aumenta o grau de satisfação dos usuários. Como recomendação, sugere-se a aplicação do programa de manutenção preventiva, visto que todo o material desempenha seu papel somente por um período determinado, e esse 
período é mais curto quanto maior forem as interferências externas. Assim, os revestimentos por serem os que mais sofrem com agentes agressivos, tanto do ambiente externo, quanto interno, requerem maiores cuidados com revisão e manutenção periódicas, muitas vezes simples como a limpeza e repintura, mas eficientes.

Esta garantia depende diretamente da escolha dos materiais de revestimento, ou seja, de sua qualidade e adequação e da forma como os mesmos foram ou estão sendo manipulados e aplicados (cada material, que possui comportamento diferenciado, apresenta especificação técnica própria e requer mão-de-obra especializada). Qualquer falha em um desses itens irá, mais cedo ou mais tarde, "aparecer" no acabamento, sob a forma de anomalias.

\section{REFERÊNCIAS}

ASSOCIAÇÃO BRASILEIRA DE NORMAS TÉCNICAS. NBR 5674: Manutenção de edificações Procedimento. Rio de Janeiro, 2012.

ASSOCIAÇÃO BRASILEIRA DE NORMAS TÉCNICAS. NBR 13749: Revestimentos de paredes e tetos de argamassas inorgânicas - Especificação. Rio de Janeiro, 2013.

ASSOCIAÇÃO BRASILEIRA DE NORMAS TÉCNICAS. NBR 5674 - Manutenção de edificações Procedimentos. Disponível em: https://www.docsity.com/pt/nbr-5674-2012/4881673/. Acesso em: 06 nov. 2019

ASSUNÇÃO, K. A. Análise de manifestações patológicas de revestimento em fachada de edificação histórica: Estudo de Caso no Município de Estância. 2019. 111 f. Tese (Livre-Docência) - Instituto Federal de Educação, Ciência e Tecnologia de Sergipe, Departamento de Engenharia Civil. Estância, SE, Brasil, 2019.

BRICK, E. M. J.; MOREIRA, L.P.; KRÜGER, J. A. Estudos das patologias em estruturas de concreto provenientes de erros em ensaios e em procedimentos executivos. Encontro de Engenharia e Tecnologia dos Campos Gerais, 2013.

FILHO, Armando Carneiro Pereira do Rêgo. Memória da Escola Politécnica de Pernambuco: Saga de uma instituição educacional, Recife 1981

GIORDANI, A. Z. Levantamento e diagnóstico das manifestações patológicas em fachadas de edificações localizadas no campus da UFSC. 2016. 100 f. Tese (Livre-Docência) - Universidade Federal de Santa Catarina, Departamento de Engenharia Civil. Florianópolis, SC, Brasil, 2016.

MOESCO, J.; BORDIN, F.; VERONEZ, M. R.; KULAKOWSKI, M.P. Termografia infravermelha na deteç̧ão de Manifestações Patológicas em Fachadas com Revestimento Argamassado. In: CONGRESSO INTERNACIONAL SOBRE PATOLOGIA E RECUPERAÇÃO DE ESTRUTURAS, 2015, São Leopoldo, Rio Grande do Sul. Anais... João Pessoa: CINPAR, 2015. v. 1, p. 1- 13.

ROCHA, E.A e MONTEIRO, E.C.B. Manifestações Patológicas em Estruturas de Concreto. 5. ed. Recife: Bookman, 2017.

SAHADE, Renato Freua. Avaliação de sistemas de recuperação de fissuras em revestimentos de vedação 2005. 169 f. Tese (Livre-Docência) - Instituto de Pesquisas Técnológicas do Estado de São Paulo Departamento de Engenharia Civil. São Paulo, SP, Brasil, 2005.

SILVA, C.; COELhO, F.; BRITO, J.; SILVESTRE, J.; PEREIRA, C. Statistical survey on inspection, diagnosis and repair of architectural concrete surfaces, Journal osf performance of constructed facilities, Reston, v. 31, n.6, p. 2-9, 2017.

TUTIKIAN, Bernardo; PACHECO, Marcelo. Inspeção, diagnóstico e prognóstico na construção civil. Boletim Técnico no 1 - Asociación Latinoamericana de Control de Calidad, Patología e Recuperación de la Construcción ALCONPAT Int. Março, 2013.

ZANOVI, V. A> G. Influência dos agentes climáticos de degradação no comportamento higrotérmico de fachadas em Brasília. Tese de doutorado, Universidade de Brasília, 2016. 